\title{
The examination of the assessment and evaluation course achievements of university students based on discriminant and logistic regression analysis
}

\author{
Fazilet Taşdemir ${ }^{1 a}$, and D.Bahar Şahin ${ }^{1}$ \\ ${ }^{1}$ Faculty of Educational, Recep Tayyip Erdoğan University, Rize, 53200, Turkey
}

\begin{abstract}
In this study, it is intended to analyze pass/fail classification determined according to the assessment and evaluation course grades of third-year university students with logistic regression analysis and discriminant analysis. This research is a correlational survey in scan model. Appropriate sampling method of non-selection sampling methods was used in determining the research group. Research Group is constitute $\mathrm{d}$ by 410 third-year students of Faculty of education at Recep Tayyip Erdogan University in 2013-2014 academic year. In the process of data collection, assessment and evaluation success test developed by researchers and assessment and evaluation test developed by "personal information" form and researchers with validity and reliability analysis were used. The severity levels of the variables active in classification (pass-fail) in the model was determined logistic regression analysis. Hosmer and Lemeshow test result showed that the model-data fit is provided ( $p>0$. 05). In this case, the change that occurred in the fit of the model has been found to be significant. The total percentage of correct classification of the discriminant function groups were higher than the percentage of the logistics analysis.
\end{abstract}

Keywords: Assessment-evaluation course success, undergraduate entry points, period for the exam preparation.

\section{Introduction}

Assessment is based on to determine the degree to which an object, an individual has a specific qualification or property [5]. Assessment and evaluation are an integral and complementary part of the educational process. When education planning and implementation stages in each field are examined, assessment and evaluation is an application that completes the education process [1]. The achievements of university

\footnotetext{
${ }^{\text {a }}$ Corresponding author: fazilet.tasdemir@erdogan.edu.tr
} 
students in these courses vary compared to other courses [3]. It is observed that it is necessary to examine course success classification of students.

The aim of this research is to analyze the classification accuracy designated as pass/fail for the assessment and evaluation course success of third-year university students. Following questions arose in response to these general objectives:

1.How the classification accuracy of pass/fail student groups determined according to the undergraduate academic achievement grade point average, period for the exam preparation and undergraduate entry points assessment and evaluation of test score change;

1.a. According to the discriminant analysis,

1.b. According to logistic regression analysis?

\section{Method}

This research is a correlational model. Correlational researches are researches in which the relationship between two or more variables are reviewed without the intervention to these variables. It can be argued that correlational researches are important researches that provides research tips for disclosure of the relations between the variables, and more senior research to be made of those relations [2].

\subsection{Participants}

Appropriate sampling method of non-sampling method was used in determining the selection of research group [4]. Appropriate sampling method aims to set up sampling starting from the most accessible responder until reaching a group of researchers in required size. Research Group consists of 410 third year students of the Faculty of education in Rize Province with an aim to provide research as mentioned in the research methods.

\subsection{Procedure}

In the process of data collection, assessment and evaluation success test was used developed within the scope of the course in the 2013-2014 academic year with validity and reliability analysis. The test scores obtained in the study constitutes student data. Student academic success grade point averages are provided by student affairs and high school academic achievement, grade point average and graduate entry points are provided from personal information form.

\section{Statistical Analysis}

The classification accuracy of the sub-objective variables including undergraduate grade point average, test preparation period and graduate entry points of pass/fail student groups determined according to assessment and evaluation of test score; when group statistics were examined according to the discriminant analysis; core values in relation to test scores were found.

Table 1. Wilks ' Lambda Test Of Equality Of Group Initiatives

\begin{tabular}{lccc}
\hline Points & $\begin{array}{c}\text { Wilks' Lam } \\
\text { bda }\end{array}$ & $\mathrm{F}$ & $\mathrm{p}$ \\
\hline test preparation period & .978 & 4.402 & .037 \\
\hline graduate entry points & .979 & 4.090 & .044 \\
\hline undergraduate grade point average & .867 & 29.816 & .000 \\
\hline
\end{tabular}


When the significant level of each independent variable are examined, difference between the groups are significant in high school grade point average academic achievement "[F $(258,066)=1.0 .0, \mathrm{p}<.05]$ ", exam preparation time " $[\mathrm{F}(258,066)=4.090$, $\mathrm{p}<.05]$ ", and undergraduate grade point average academic achievement "[F $(258,066)=$ $26.816, \mathrm{p}<.05]^{\prime \prime}$ points as shown in table 1 .

Table 2. Pass/Fail Students Classification Results

\begin{tabular}{llllll}
\hline Points & Pass & & Fail & Total \\
\hline & $\mathrm{f}$ & $\%$ & $\mathrm{f}$ & $\%$ & $\mathrm{f}$ \\
\hline Pass & 275 & 81.6 & 62 & 18.3 & 337 \\
\hline Fail & 17 & 23.2 & 56 & 76.7 & 73 \\
\hline Total & 292 & & 118 & & 410 \\
\hline
\end{tabular}

When Table 2 showing classification results is examined, 275 of 337 students in pass group (81.6\%) and 56 of 73 students in fail group (47.7\%) are classified as "correct".

The classification accuracy of the sub-objective variables including undergraduate grade point average, test preparation period and graduate entry points of pass/fail student groups determined according to assessment and evaluation of test score;

When group statistics is examined according to logistic regression analysis;

Table 3. Classification Status according to Logistic Regression Analysis

\begin{tabular}{lllll}
\hline & $\begin{array}{l}\text { Actual/Observed } \\
\text { Status }\end{array}$ & Estimated Status & $\begin{array}{l}\text { Percentage Of Correct } \\
\text { Classification }\end{array}$ \\
\hline Step 1 & Fail & Pass & \\
& Fail & 42 & 31 & 57.5 \\
\cline { 2 - 5 } & Pass & 71 & 266 & 78.9 \\
\hline Total Percentage Of Correct Classification & & & 75.1 \\
\hline
\end{tabular}

According to the classification obtained as a result of the logistic regression model, as seen in Table 3, 42 of 73 students in fail group are classified as correct and 31 as incorrect, the percentage of accurate classification is $57.5 \%$. According to the classification obtained as a result of the logistic regression model, as seen in Table 3, 42 of 73 students in fail group are classified as correct and 31 as incorrect, the percentage of accurate classification is $57.5 \%$. 266 of 337 students in pass group are classified as correct and 71 as incorrect; the percentage of accurate classification is $78.9 \%$. The total percentage of correct classification for the intended model is $75.1 \%$.

\section{Result and Discussion}

When classification accuracy results of pass/fail students groups determined according to undergraduate academic achievement grade point average, period for the exam preparation and undergraduate entry points are examined, it was observed that there are more accurate resuits in discriminant analysis than logistic regression analysis. According to these results, similar researches may be recommended to the researchers in which the course achievements, attitude, interest, etc of students are analyzed with allocation as a multivariate statistical methods together with analysis (discriminant, clustering, logistic regression, structural equation model) for classification purposes. 


\section{References}

1. Allison, Paul D. (1999). Comparing Logit and Probit Coefficients Across Groups. Sociological Methods and Research 28:186-208.

2. Büyüköztürk, Ş. and etc. (2008). Bilimsel Araştırma Yöntemleri, Ankara: PegemA Yayınları.

3. Carter V, Good E. (1973 ) Dictionary of Education. 4nd ed, New York, McGraw Hill Book Company,

4. Cohen, L. and Manion, L. (1994) Research Methods in Education. 4th. ed. London and New York: Routledge.

5. Kan, A.(2006), Eğitimde Ölçme ve Değerlendirme, “Ödev ve Projeler”, (Ed. H. Atılgan), Anı Yayıncılık, Ankara. 